\title{
Sleipner Soğuk İş Takım Çeliğinin Elektro-Erozyon Tezgahında Bakır Krom Zirkonyum Alaşımı Elektrot ile İşlenmesinde İşleme Parametrelerinin Kerf ve Yüzey Pürüzlüllüğü Üzerine Etkisinin İncelenmesi
}

\author{
Ferhat CERİTBINMEZ ${ }^{1 *}$, Ahmet YAPICI ${ }^{2}$
}

\begin{abstract}
$\ddot{\mathbf{O} z}$
Bu çalışmada 60-62 HRC sertlik değerine sahip Sleipner Soğuk İş Takım Çeliğinden Bakır Krom Zirkonyum Alaşımı Elektrot kullanılarak elektro erozyon işleme (EEI) yöntemi ile talaş kaldırılmıştır. Bu kapsamda üç farklı boşalım akımı $(6,25 ; 12,5 ; 25 \mathrm{~A})$, üç farklı ark süresi $(3 ; 6 ; 9 \mu \mathrm{s})$, üç farklı bekleme süresi $(4 ; 6 ; 8 \mu \mathrm{s})$ işleme parametreleri kullanılarak deneyler gerçekleştirilmiştir. Kullanılan işleme parametrelerinin yüzey pürüzlülüğü, kerf açısı, işleme süresi gibi temel performans çıktıları üzerindeki etkileri analitik ölçümler ve makro analizler ile belirlenmiştir. Yapılan analizler neticesinde bekleme süresinin artması ile işleme süresi büyük ölçüde artmış boşalım akımının ve ark süresinin artması ile azalmıştır. Boşalım akımının artması iş parçası ve elektrot arasında kıvılcımlanmayı arttırarak noktasal erime ve buharlaşma arttırmıştır bunun neticesinde yüzey pürüzlülüğü artmıştır. Düşük ark süresi ve yüksek bekleme süresi elektrotu birim zamanda daha fazla çalıştırarak aşındırmış bu aşınma sonucunda ortalama kerf açısı artmıştır. Boşalım akımının \% 100 ve \% 300'lük artışı neticesinde ortalama yüzey pürüzlülügü sırasıyla $\% 62$ ve \% 87 oranında artmıştır. EEİ esnasında hem iş parçasının hemde elektrot malzemesinin aşınmasıyla ortaya çıkan debris ve kalıntıların ortamdan tahliye edilememesi veya elektrot uç kısımlarına yapışması işleme süresinde, yüzey pürüzlülügünde ve elektrot aşınmasına bağlı kerf oluşumunda düzensizliğe sebep olmuştur.
\end{abstract}

Anahtar Kelimeler: EEİ, Kerf, Yüzey pürüzlülüğü, Sleipner.

\section{Investigation of the Effect of Processing Parameters on Kerf and Surface Roughness in the Machining of Sleipner Cold Work Tool Steel with Copper Chromium Zirconium Alloy Electrode in Electro-Erosion Machine}

\begin{abstract}
In this study, metal was removed by electro erosion processing method using Copper Chromium Zirconium Alloy Electrode from Sleipner Cold Work Tool Steel with 60-62 HRC hardness value. In this context, experiments were carried out using three different discharge currents $(6,25 ; 12,5 ; 25 \mathrm{~A})$, three different pulse on times $(3 ; 6 ; 9 \mu \mathrm{s})$, three different pulse off times $(4 ; 6 ; 8 \mu \mathrm{s})$. The effects of the used processing parameters on the fundamental performance outputs such as surface roughness, kerf angle, processing time were determined by analytical measurements and macro analysis. As a result of the analysis, the processing time increased significantly with the increase in the pulse off time and decreased with the increase of the working current and pulse on times. The increase in the working current increased the spark between the workpiece and the electrode, increasing the point melting and evaporation, as a result of which the surface roughness increased. The electrode was worn out due to the effect of the low pulse on time and high pulse off time parameters, as it worked more per unit time, as a result of this wear, the average kerf angle increased. As a result of the $\% 100$ and $\% 300$ increase in the discharge current, the average surface roughness increased by $\% 62$ and $\% 87$, respectively. Failure to evacuate debris and residues caused by wear of both the workpiece and the electrode material during EDM or sticking to electrode tips were caused irregularity in the processing time, surface roughness and kerf formation due to electrode wear.
\end{abstract}

Keywords: EDM, Kerf, Surface roughness, Sleipner.

\footnotetext{
${ }^{1}$ Haier Europe, Candy - Hoover Group, Araştırma ve Geliştirme Merkezi, Eskişehir, Türkiye, ferhatceritbinmez@gmail.com 2̇̇skenderun Teknik Üniversitesi, Makine Mühendisliği Bölümü, Hatay, Türkiye, ahmet.yapici@iste.edu.tr
}

${ }^{1}$ https://orcid.org/0000-0002-5615-3124 $\quad{ }^{2}$ https://orcid.org/0000-0003-4274-2697 


\section{Giriş}

Soğuk iş takım çelikleri $200-250{ }^{\circ} \mathrm{C}$ altındaki soğuk uygulamalarda genellikle hassas kesme, form verme, çekme, soğuk dövme, toz presleme gibi operasyonların kalıplarında ve ekipmanlarında tercih edilen yüksek alaşımlı malzemelerdir (Rahim ve ark., 2018). Kullanım yerlerine göre mukavemet, aşınma ve sıvama direnci, tokluk, yüksek sertlik, işlenebilirlik ve yüzey kalitesi bu çeliklerden beklenen en önemli özelliklerdir (Zappelino ve ark., 2020). Sahip oldukları mekanik ve fiziksel özelliklerinden dolayı bu çeliklerin kullanım yerlerine ve son şekillerine getirilebilmeleri için uygun talaşlı veya talaşsız imalat yöntemlerinin kullanılması takım aşınması, işleme süresi, maliyet ve işlem kalitesi açısından büyük önem taşır (Srithar ve ark., 2014). Sertliğinden ve diğer mekanik özelliklerinden bağımsız olarak elektrik iletkenliği olan bütün malzemeler üzerlerine uygulanan kıvılcım atlamaları ile noktasal olarak ergime ve buharlaşma prensibine dayanan talaş kaldırma metodu Elektro Erozyon İşleme (EEİ) yöntemi kullanılarak işlenebilmektedir (Kalyon ve Fatatit, 2019; Lee ve Li, 2001). Bu yöntemde dielektrik sıvı altında, istenilen formda hazırlanmış elektrot (katot) malzeme iş parçası (anot) üzerine yaklaştırılarak elektrodun formu iş parçası üzerinde elektro termal talaş kaldırma ile aktarılmış olur (Bari ve ark, 2017; Gupta ve ark, 2016). Havacılık ve otomotiv sektörü başta olmak üzere birçok kalıp imalatında yaygın olarak kullanılan, konvensiyonel yöntemlerle kesilmesi pek mümkün olmayan veya yüksek maliyetli olan, sertliği yüksek malzemeler EEİ yöntemi kullanılarak iş parçasına mekanik temas ve gerilme olmadan işlenebilmektedir (Mohanty ve ark, 2014; Li ve ark, 2015; Singh ve ark, 2004). EEİ yönteminde seçilen işleme parametrelerinin ve kullanılan elektrot malzemesinin iş parçası üzerindeki yüzey pürüzlülüğü, kerf açısı, işleme süresi gibi performans çıktıları üzerindeki etkileri temel kalite göstergeleridir. Payal ve diğerleri, EN-31 takım çeliğinin EEİ yöntemiyle işlenmesinde bakır, pirinç, grafit elektrot ve dielektrik sıvı olarak gaz yağı kullanarak elde edilen yüzeylerin pürüzlülüğünü ve talaş kaldırma oranlarını analiz etmişlerdir. Taramalı Elektron Mikroskobu (SEM) ve optik mikroskop analizleri neticesinde yüksek boşalım akım parametresinde bakır elektrot kullanımında en yüksek talaş kaldırma oranına ulaşılmış, pirinç elektrot kullanımda ise en iyi yüzey kalitesi elde edilerek daha az talaş kaldırma oranına ulaşılmıştır. Grafit elektrot kullanımında çalışma yüzeyinde eşit olmayan ısı dağılımı nedeniyle daha kötü bir yüzey kalitesi elde etmişlerdir (Payal ve ark, 2008). Nas ve diğerleri, bakır ve grafit elektrot kullanarak AISI 1.2738 malzemesinden EEİ yöntemi ile talaş kaldırarak en düşük yüzey pürüzlülüğü için ideal parametreler belirlemeye çalışmışlardır. İşleme parametreleri olarak 100, 200 ve $300 \mu$ s vurum süreleri; 10, 20 ve $30 \mu$ s bekleme süreleri ve 10, 20 ve 30 A boşalım akımları kullanılarak elde edilen yüzeylerin pürüzlülüğü Taguchi Orthogonal Array Design L54 istatiksel metodu kullanılarak analiz edilmiştir. Yapılan analizler neticesinde yüzey pürüzlülüğünde en etkili parametreler sırasıyla boşalım akımı, vurum süresi, bekleme süresi ve elektrot olarak 
belirlenmiştir. En düşük ortalama yüzey pürüzlülük değerleri bakır elektrot kullanımında Ton $300 \mu$ s, Toff $30 \mu \mathrm{s}$ ve 10 A parametrelerinin seçilmesi neticesinde 4,73 $\mu \mathrm{m}$ olarak, grafik elektrot kullanımında ise Ton $100 \mu$ s Toff $10 \mu$ s ve 20 A parametreleri seçilmesi neticesinde 4,35 $\mu$ m olarak hesaplanmıştır (Nas ve ark, 2018). Lee ve diğerleri, EEİ parametrelerinin AISI 1045 karbon çeliğinin yüzey bütünlüğünün çeşitli yönleri üzerindeki etkisini belirlemek için düşük aşınma oranlı bakırtungsten elektrot ile 1,5 mm çapında küçük alanlı elektro-erozyon işleme gerçekleştirmişlerdir. Yüksek boşalım akımı ve vurum sürelerinde talaş kaldırma oranının, yüzey pürüzlülügünün, EEİ etki alanının ve curuf tabakasının artma eğiliminde olduğunu vurgulamışlardır (Lee ve ark, 2004). Yılmaz ve diğerleri, AISI 1040 çeliği üzerinde EEİ yöntemi ile mikro deliklerin delinebilirliğini deneysel olarak inceleyerek üç farklı boşalım akımı (6, 12, 24 A), üç farklı elektrot devir sayısı (200, 400, 600 dev/dak), sabit vurum süresi (12 $\mu \mathrm{s})$, sabit vurum aralığı (3 $\mu \mathrm{s})$ ve üç farklı dielektrik sıvı uygulama basıncı (40, 80, 120 bar) işleme parametrelerinin işleme hızı, elektrot aşınma hızı ve bağıl aşınma gibi performans çıktıları üzerindeki etkilerini analiz etmişlerdir. Yapılan analizler neticesinde delik delme sürelerini etkileyen en önemli parametrenin boşalım akımı alduğunu vurgulayarak; boşalım akımının artması ile iş parçası işleme hızı, elektrot aşınma hızı ve bağıl aşınmanın arttığını bildirmişlerdir (Özdemir ve ark, 2015). Guu, EEİ yöntemiyle işlenmiş AISI D2 takım çeliğinin yüzey morfolojisini, yüzey pürüzlülüğünü ve mikro çatlak analizini atomik kuvvet mikroskobu (AFM) tekniği ile analiz etmiştir. AFM tekniğini, nanometre ölçeğinde üç boyutlu bir görüntü elde etmek ve üzerinde oluşan mikro çatlakların derinliğini değerlendirmek için başarıyla uygulayarak; EEİ'den sonraki yüzey dokusunun, işleme sırasındaki deşarj enerjisi tarafından belirlendiğini, daha yüksek bir deşarj enerjisinin daha zayıf bir yüzey yapısı ile sonuçlandığını raporlayarak deşarj enerjisinin artışının yüksek yüzey pürüzlülüğü ve artan mikro çatlak derinliğine sebep olduğunu vurgulamıştır (Guu, 2005). Kalyon, demir dışı alaşımlardan olan alüminyumun 6082 T-651 alaşımını bakır ve grafit elektrot kullanarak EEİ metodu ile işlemiştir. Optimum yüzey pürüzlülüğü ve iş parçası işleme hızı (İ̈H) parametrelerini 6, 12, 25 A boşalım akımı ve 50, 100, $200 \mu$ s vurum süresi değerlerini kullanarak Taguchi optimizasyonu ile belirlemiştir. Anova analizini kullanarak boşalım akımının yüzey pürüzlülüğüne etkisinin \% 90,09; İ̈H'a etkisinin \% 95,54 oranında olduğunu rapor etmiştir (Kalyon, 2019). Yıldız, magnezyum-kalsiyum (Mg-0,8Ca) alaşımının EEİ yöntemiyle işlenmesinde boşalım akımı ve vurum süresinin işleme performasına etkisini (ANOVA) ve regresyon analizi gibi istatistiksel metotlarlarla belirlemeye çalışmıştır. Boşalım akımı olarak 10, 15, 20, 25 A ve vurum süresi olarak 20,40, 60, $80 \mu \mathrm{sn}$ parametreleri ile yapılan çalışmalar neticesinde $4,22 \mathrm{~mm}^{3} / \mathrm{sn}$ talaş kaldırma oranı ve \% 0,37 ortalama elektrot aşınma oranına ulaşıldığını, yüzey pürüzlülük değerininde 9,69 $\mu \mathrm{m}$ olabildiğini bildirmiştir. Boşalım akımının talaş kaldırma oranına etkisinin vurum süresinden daha fazla olduğu daha fazla talaş kaldırma oranı için daha yüksek değerler kullanılmasını önermiştir (Yıldız, 2017). Kalyon, AISI D2 soğuk iş takım çeliğini bakır elektrot kullanarak EEİ yöntemi ile 
işlemiştir. İşleme parametreleri olan 6, 12, 25 A boşalım akımı ve 50, 100, $200 \mu$ sn vurum süresi değerlerinin yüzey pürüzlülüğü, iş parçası işleme hızı, elektrot aşınma hızı ve bağıl aşınma üzerindeki etkilerini belirlemiştir. Deneysel olarak SEM ve mikroskop analizleri neticesinde vurum süresi ve boşalım akımının artmasıyla yüzey pürüzlülüğünün, iş parçası işleme hızının ve elektrot aşınma hızının arttığını rapor ederek; düşük boşalım akımı ve vurum süresi değerlerinin kullanılmasıyla yüksek yüzey kalitesi ve ölçüsel hassasiyetin elde edilebileceğini belirtmiştir (Kalyon, 2020). Literatür çalışmaları incelendiğinde EEİ yöntemi kullanılarak farklı yapıdaki soğuk / sıcak iş takım çelikleri, alaşım malzemeleri iş parçası olarak seçilmiş; bu malzemelerden talaş kaldırmak için bakır, pirinç, grafit gibi malzemeler elektrot olarak kullanılmıştır. Yapılan çalışmalarda boşalım akımı, vurum ve bekleme süresi gibi işleme parametreleri değişken olarak kullanılarak; yüzey pürüzlülüğü, iş parçası işleme hızı, talaş kaldırma oranı, elektrot aşınma oranı gibi performans çıktıları değerlendirilerek işleme kaliteleri belirlenmeye çalışılmıştır. EEİ yönteminde kullanılan, kıvılcımlanma ile iş parçasından talaş kaldırmak için kullanılan elektrot malzemesinin erozyon başlangıcındaki ölçüleri ile işlem sonundaki ölçüleri aynı değildir. Termal etkiler ve seçilen işlem parametrelerinin etkisiyle elektrodun uç kısımlarında termal yoğunluk ve kıvılcımlanmalar sebebi ile deformasyonlar olur ve elektrot aşınır. Bu sebepten dolayı iş parçası üzerinde kerf açısı meydana gelir. Ortaya çıkan bu kerf açısı neticesinde iş parçasında elde edilen formun ölçüleri değişir. Bu değişimlerden kaynaklanan hatalı parça üretimi, tekrar işleme ihtiyacından dolayı ortaya çıkacak maliyet ve işleme zamanı gibi istenmeyen problemler bertaraf edilmeli veya belirli sınırlarda tutulmalıdır. Bu çalışmada literatürden farklı olarak 60-62 HRC sertlik değerine sahip Sleipner Soğuk İş Takım Çeliğinden Bakır Krom Zirkonyum Alaşımı Elektrot kullanılarak EEİ yöntemiyle talaş kaldırılmıştır. Bu kapsamda farklı işleme parametrelerinin ortalama kerf açısı ve yüzey pürüzlülüğü, işleme süresi gibi temel performans çıktıları üzerindeki etkileri analitik ölçümler ve makro analizler ile tespit edilmiştir. Bu makaleden elde edilen sonuçlar, en iyi yüzey kalitesinin elde edilmesinde ayrıca kerf probleminin asgari düzeyde tutulmasında endüstriyel uygulamalar için çok değerli bir referans olma potansiyelini barındırmaktadır.

\section{Materyal ve Metot}

\subsection{Sleipner İş Parçası}

Uddeholm Sleipner genel amaçlı soğuk iş için kullanılan bir krom-molibden-vanadyum alaşımlı takım çeliği olarak ; iyi aşınma direnci, yüksek basınç dayanımı, 1sıl işlem uygunluğu ve yüksek sertlik, WEDM (Wire Electric Discharge Machining) ve EDM (Electric Discharge Machining) işlemeye uygunluk gibi özelliklerinden dolayı bir çok kullanım alanına sahiptir. Bu 
çalışmada EEİ yöntemiyle talaş kaldırmak için Sleipner malzeme iş parçası olarak kullanılmıştır. Sleipner malzemeler Alseko Metal firmasından ısıl işlemli olarak temin edilerek teknik özellikleri; kimyasal bileşenleri ve mekanik özellikleri sırası ile Tablo 1 ve 2'de belirtilmiştir.

Tablo 1. Sleipner Kimyasal bileşeni

\begin{tabular}{|c|c|c|c|c|c|}
\hline $\begin{array}{c}\text { Karbon } \\
(\% \mathrm{C})\end{array}$ & $\begin{array}{c}\text { Silisyum } \\
(\% \mathrm{Si})\end{array}$ & $\begin{array}{c}\text { Manganez } \\
(\% \mathrm{Mn})\end{array}$ & $\begin{array}{c}\text { Krom } \\
(\% \mathrm{Cr})\end{array}$ & $\begin{array}{c}\text { Molibden } \\
(\% \mathrm{Mo})\end{array}$ & $\begin{array}{c}\text { Vanadyum } \\
(\% \mathrm{~V})\end{array}$ \\
\hline 0,9 & 0,9 & 0,5 & 7,8 & 2,5 & 0,5 \\
\hline
\end{tabular}

Tablo 2. Sleipner Mekanik Özellikleri

\begin{tabular}{|c|c|c|c|c|c|}
\hline $\begin{array}{c}\text { Sertlik } \\
(\mathrm{HRC})\end{array}$ & $\begin{array}{c}\text { Termal } \\
\text { İletkenlik } \\
\left(\mathrm{W} / \mathrm{m} \cdot{ }^{\circ} \mathrm{C}\right)\end{array}$ & $\begin{array}{c}\text { Özgül Is1 } \\
\text { S1 ğas1 } \\
\left(\mathrm{J} / \mathrm{kg} \cdot{ }^{\circ} \mathrm{C}\right)\end{array}$ & $\begin{array}{c}\text { Elastisite } \\
\text { Modülü } \\
\left(\mathrm{kN} / \mathrm{mm}^{2}\right)\end{array}$ & $\begin{array}{c}\text { Termal } \\
\text { Genleşme } \\
\text { katsay1s1 }\end{array}$ & $\begin{array}{c}\text { Yoğunluk } \\
\left(\mathrm{g} / \mathrm{cm}^{3}\right)\end{array}$ \\
\hline $60-62$ & $20-25$ & 460 & 205 & $12,7 \times 10^{-6}$ & 7,73 \\
\hline
\end{tabular}

\subsection{Cupro MAX CuCrZr Elektrot}

Cupro MAX CuCrZr Bakır Krom Zirkonyum Alaşımı yapısında ihtiva ettiği krom ve zirkonyum sayesinde saf bakıra göre daha yüksek sertliğe sahiptir. Ayrıca elektrik iletkenliği en yüksek olan bakır alaşımlarından biridir. Sahip olduğu üstün özelliklerinden dolayı direnç kaynağında elektrot ucu ve diski, alüminyum enjeksiyon makina pistonlarında, plastik ejeksiyon makinalarının püskürtme memelerinde ve dalma erozyon tezgahlarında elektrot malzemesi olarak yaygın olarak kullanılmaktadır. Bu çalışmada elektrot olarak kullanılan Cupro MAX CuCrZr Sağlam Metal firmasından temin edilerek, kimyasal bileşenleri ve mekanik özellikleri sırası ile Tablo 3 ve 4'te belirtilmiştir.

Tablo 3. Cupro MAX CuCrZr Kimyasal bileşeni

\begin{tabular}{|c|c|c|c|}
\hline $\begin{array}{c}\text { Krom } \\
(\% \mathrm{Cr})\end{array}$ & $\begin{array}{c}\text { Zirkonyum } \\
(\% \mathrm{Zr})\end{array}$ & $\begin{array}{c}\text { Diğer } \\
(\text { Maksimum })\end{array}$ & $\begin{array}{c}\text { Bakır } \\
(\% \mathrm{Cu})\end{array}$ \\
\hline 1 & 0,1 & 0,2 & Kalan \\
\hline
\end{tabular}

Tablo 4. Cupro MAX CuCrZr Mekanik Özellikleri

\begin{tabular}{|c|c|c|c|c|c|}
\hline $\begin{array}{c}\text { Sertlik } \\
(\mathrm{HB})\end{array}$ & $\begin{array}{c}\text { Çekme } \\
\text { Dayanım1 } \\
\left(\mathrm{N} / \mathrm{mm}^{2}\right)\end{array}$ & $\begin{array}{c}\text { Akma } \\
\text { Dayanım1 } \\
\left(\mathrm{kN} / \mathrm{mm}^{2}\right)\end{array}$ & $\begin{array}{c}\text { Elastisite } \\
\text { Modülü } \\
\left(\mathrm{kN} / \mathrm{mm}^{2}\right)\end{array}$ & $\begin{array}{c}\text { Uzama } \\
(\%)\end{array}$ & $\begin{array}{c}\text { Yoğunluk } \\
\left(\mathrm{g} / \mathrm{cm}^{3}\right)\end{array}$ \\
\hline $120-140$ & $400-500$ & $320-410$ & 122 & 18 & 8,9 \\
\hline
\end{tabular}

EEİ öncesi iş parçası ve elektrot malzemeler Charmilles Robofil 290P (WEDM), Makino S33 (CNC), Proth satıh taşlama tezgahları kullanılarak 0,005 mm ölçüm hassasiyeti ile işlenerek taşlanmıştır. Hazırlanan test malzemeleri Şekil 1'de gösterilmiştir. Tüm yüzeyleri taşlanmış 20 x 20 
mm lama bakırlar CNC tezgahlarında işlenerek 14 x $8 \mathrm{~mm}$ slot profiline getirilmiştir daha sonra EEİ yönteminde iş parçasına $3 \mathrm{~mm}$ derinliğinde dalma yaptırılmıştır.

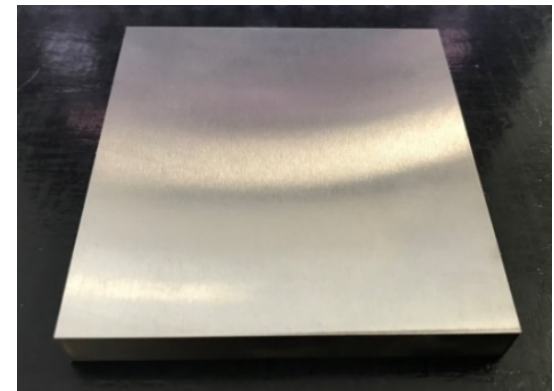

(a)

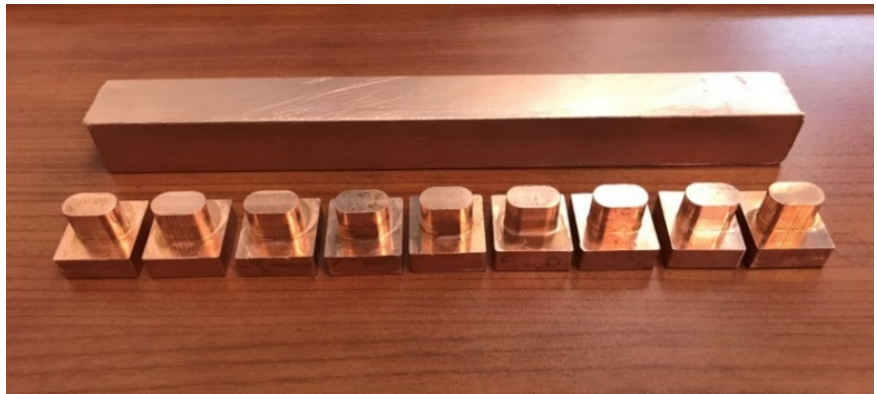

(b)

Şekil 1. Test Malzemeleri: (a) Uddeholm Sleipner (b) Cupro MAX CuCrZr

\section{3. İşleme Metodu}

Sleipner malzemenin elektro erozyon işleme yöntemi ile işlenmesinde Furkan Marka 50 Amper gücünde EDM (electric discharge machining) makina kullanılmıştır. Elektrot ve iş parçası arasındaki talaşın tahliyesi için Eralube marka dielektrik sıvı spiral metal hortumlar vasıtası ile püskürtülerek erozyon işlemi dielektirk sıvı altında gerçekleştirilmiştir (Şekil 2). Deney öncesi iş parçasının ve elektrotların yüzeyleri hassas taşlanarak her bir deney öncesi elektrot tutucu vasitasıyla diklik ve merkezleme ayarı yapılmıştır. Erozyon öncesi dielektrik sıvı, iş parçasını tamamen dielektrik sıvı altında bırakacak şekilde spiral metal hortumlar ile püskürtülmüştür ve erozyon işlemi sonrası ortamdan tahliye edilmiştir.

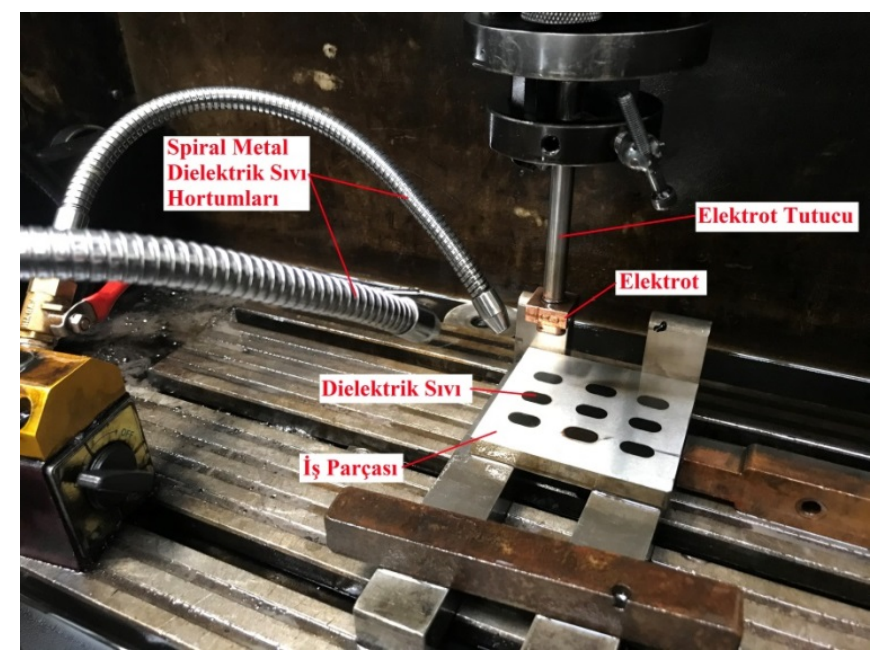

Şekil 2. Elektro Erozyon İşlemi 


\section{4. İşlenen Parçaların Analiz Yöntemleri}

EEİ sonrası test malzemesi yüksek basınçlı hava kullanılarak dielektrik sıvı ve curuf kalıntılarından temizlenmiştir. Talaş kaldırma işlemi sonrası açılan slotların farklı derinlikte olduğu görülmüştür bu sebeple Mitutoyo Mihengir’e bağlanan yüzey pürüzlülük ölçüm dedektörü (tarama ünitesi) yardımı ile işlenen kanallardan hassas ölçümler alınmıştır. Yüzey pürüzlülüğü ölçümlerinde Mitutoyo SJ200 marka taşınabilir yüzey pürüzlülük test cihazı kullanılmıştır (Şekil 3). Dedektör ucunda bulunan, dikey ve yatay hareket kabiliyetine sahip sürücünün $3 \mathrm{~mm}$ derinliğe kadar temas edebilmesi neticesinde ölçümler sorunsuzca tamamlanmıştır. Ayrıca her bir yüzeyden alınan 3 farklı ölçüm sonucunun yakın değerlerde olduğu gözlemlenmiştir.

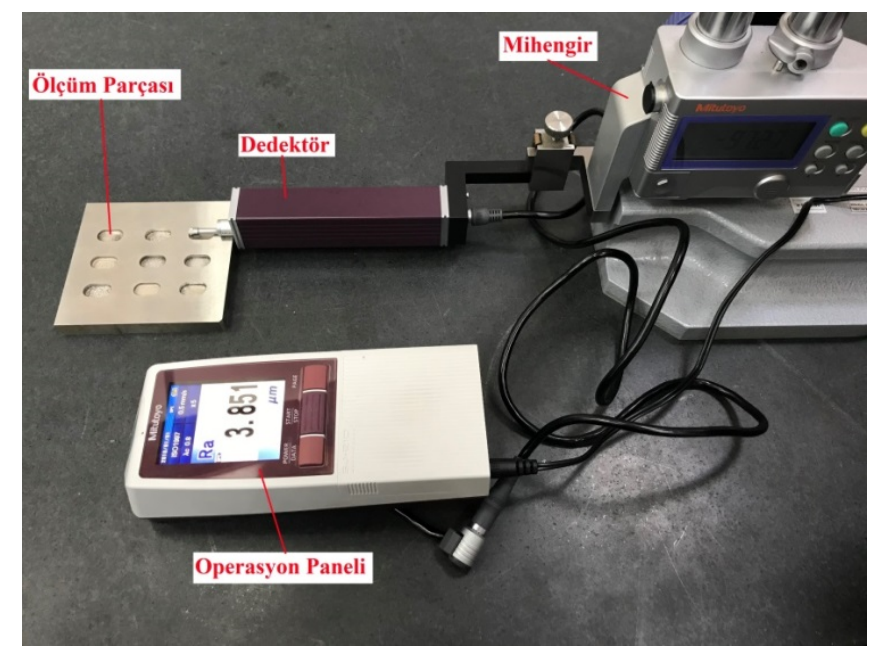

Şekil 3. Yüzey Pürüzlülüğü Ölçümü

Elektrot malzemesinin iş parçasına ilk yaklaşması sonrası her işlemde biraz daha aşınmasından kaynaklanan ve son işlemde istenilen ölçüden düşülmesi sebebi ile kerf açısı ortaya çıkmıştır. İş parçasına elektrotun ilk temas noktası $L_{t}-W_{t}$, son temas noktası $L_{b}-W_{b}$ ve derinlik $t$ değerleri ölçülerek Şekil 4' belirtilen eşitlik yardımı ile hesaplamalar yapılarak kerf açısı rapor edilmiştir. Açılan slotların eninden, boyundan ve derinliğinden Mitutoyo kumpaslar kullanılarak ölçümler alınmıştır; derinlik kumpasları ile her bir slotun farklı bölgelerinden ayrı ayrı ölçümler alınarak üç ölçüm tekrarının ortalama değerleri hesaplamalara dahil edilmiştir. Derinlik ölçümlerinde slot'un iki uç ve tam orta yüzey kısımlarından ölçümler alınmıştır. Slot'un en-boy ölçümlerinde ise en ve boy daki en uzak noktalar ölçülerek ortalama değerler rapor edilmiştir. 
$\left(T_{L}\right)=\operatorname{Arctan}\left(\frac{L_{t}-L_{b}}{2 . t}\right)$
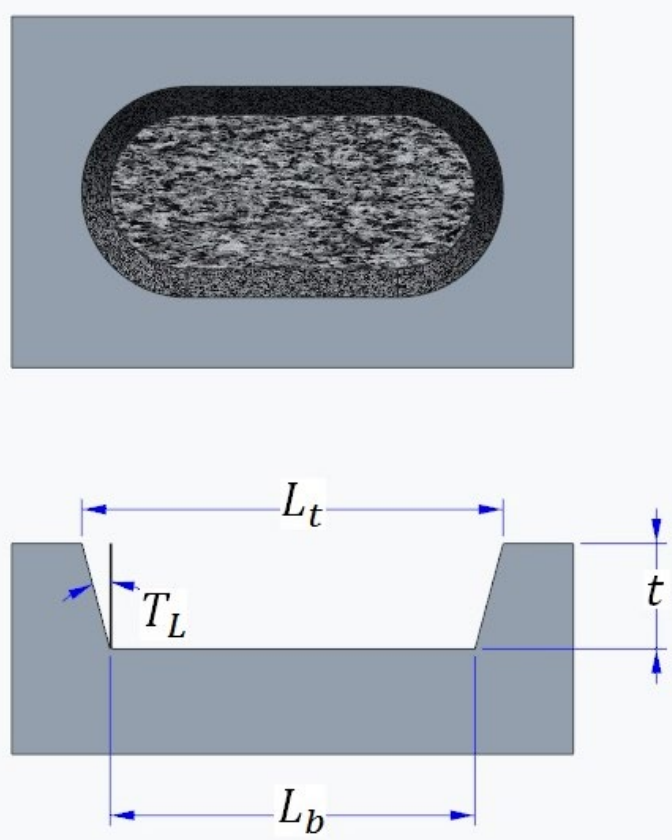

(a)
$\left(T_{W}\right)=\operatorname{Arctan}\left(\frac{W_{t}-W_{b}}{2 . t}\right)$
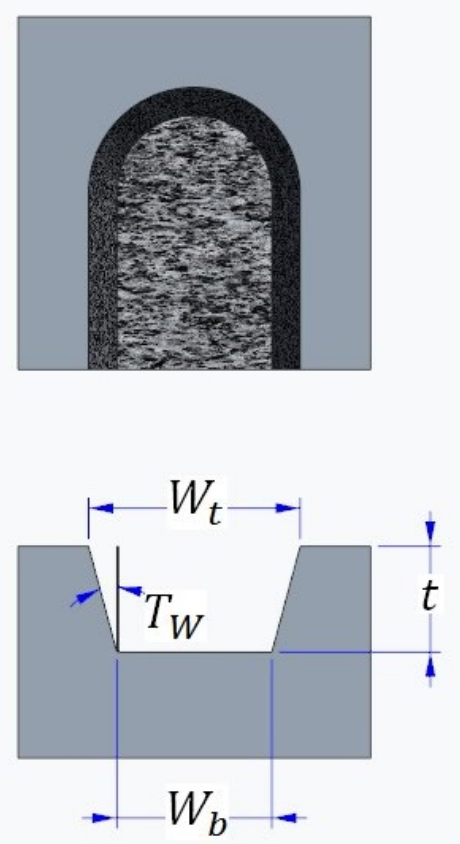

(b)

Şekil 4. Kerf Açısı: (a ) Boyuna kerf ölçümü (b) Enine kerf ölçümü

\section{Bulgular ve Tartışma}

Farklı işleme parametreleri kullanılarak yapılan deney bilgileri ve elde edilen sonuçlar Tablo 5 'te listelenmiştir. Seçilen akım, vurum ve bekleme sürelerinin değişimi ile işleme süresinin, yüzey pürüzlülügünün ve kerf açılarının değiştiği görülmüştür.

Tablo 5. EEİ parametreleri ve analiz sonuçları

\begin{tabular}{|c|c|c|c|c|c|c|c|c|}
\hline $\begin{array}{c}\text { Deney } \\
\text { No }\end{array}$ & $\begin{array}{c}\text { Boşalım } \\
\text { Akım1 } \\
(\mathrm{A})\end{array}$ & $\begin{array}{c}\text { Servo } \\
\text { Voltaj1 } \\
(\mathrm{V})\end{array}$ & $\begin{array}{c}\text { Vurum } \\
\text { Süresi } \\
(\mu \mathrm{s})\end{array}$ & $\begin{array}{c}\text { Bekleme } \\
\text { Süresi } \\
(\mu \mathrm{s})\end{array}$ & $\begin{array}{c}\text { İşleme } \\
\text { Süresi } \\
(\text { dak })\end{array}$ & $\begin{array}{c}\text { Yüzey } \\
\text { Pürüzlülüğü } \\
(\mathrm{Ra})\end{array}$ & $\begin{array}{c}\mathrm{T}_{\mathrm{L}} \\
(\text { derece })\end{array}$ & $\begin{array}{c}\text { Kerf Açıs1 } \\
(\text { derece })\end{array}$ \\
\hline 1 & 6,25 & 60 & 9 & 6 & 157 & 4,146 & 0,955 & 0,955 \\
\hline 2 & 6,25 & 60 & 6 & 4 & 26 & 6,315 & 1,896 & 1,135 \\
\hline 3 & 6,25 & 60 & 3 & 8 & 540 & 3,851 & 1,668 & 2,085 \\
\hline 4 & 12,5 & 60 & 9 & 8 & 18 & 9,200 & 2,730 & 0,188 \\
\hline 5 & 12,5 & 60 & 6 & 4 & 10 & 10,197 & 0,691 & 0,395 \\
\hline 6 & 12,5 & 60 & 3 & 6 & 72 & 3,804 & 3,021 & 2,862 \\
\hline 7 & 25 & 60 & 9 & 8 & 7 & 15,796 & 0,826 & 0,367 \\
\hline 8 & 25 & 60 & 6 & 6 & 12 & 6,346 & 1,301 & 0,651 \\
\hline 9 & 25 & 60 & 3 & 4 & 9 & 4,625 & 2,905 & 1,308 \\
\hline
\end{tabular}


EEİ yöntemi sonrası işlenen her bir yüzey ayrı ayrı analiz edilmiştir. Tane yapısı, curuf kalıntıları ve kerf bölgelerinin tespit edildiği makro görüntüler Nikon SMZ 745T mikroskop kullanılarak elde edilmiştir (Şekil 5). EEİ, bir elektro-termal işleme prosesidir. Burada elektrik enerjisi elektrik kıvılcımı (ark) oluşturmak için kullanılır ve neticesinde termal enerji ile talaş kaldırılır (Abhishek ve ark, 2017). Farklı işleme parametreleri ve özellikle yüksek akım kullanımı durumunda işlenen yüzeylerde farklı büyüklükte noktasal ergime ve buharlaşma olabilmektedir. Bu durumda girintili-çıkıntılı yüzeyler elde edilebilmektedir. Yüzey pürüzlülüğü yüzey dokusunun bir bileşenidir, Ra pürüzlülük parametresi de referans mesafe içindeki profil sapmalarının mutlak değerlerinin aritmetik ortalaması olarak tanımlanmıştır.
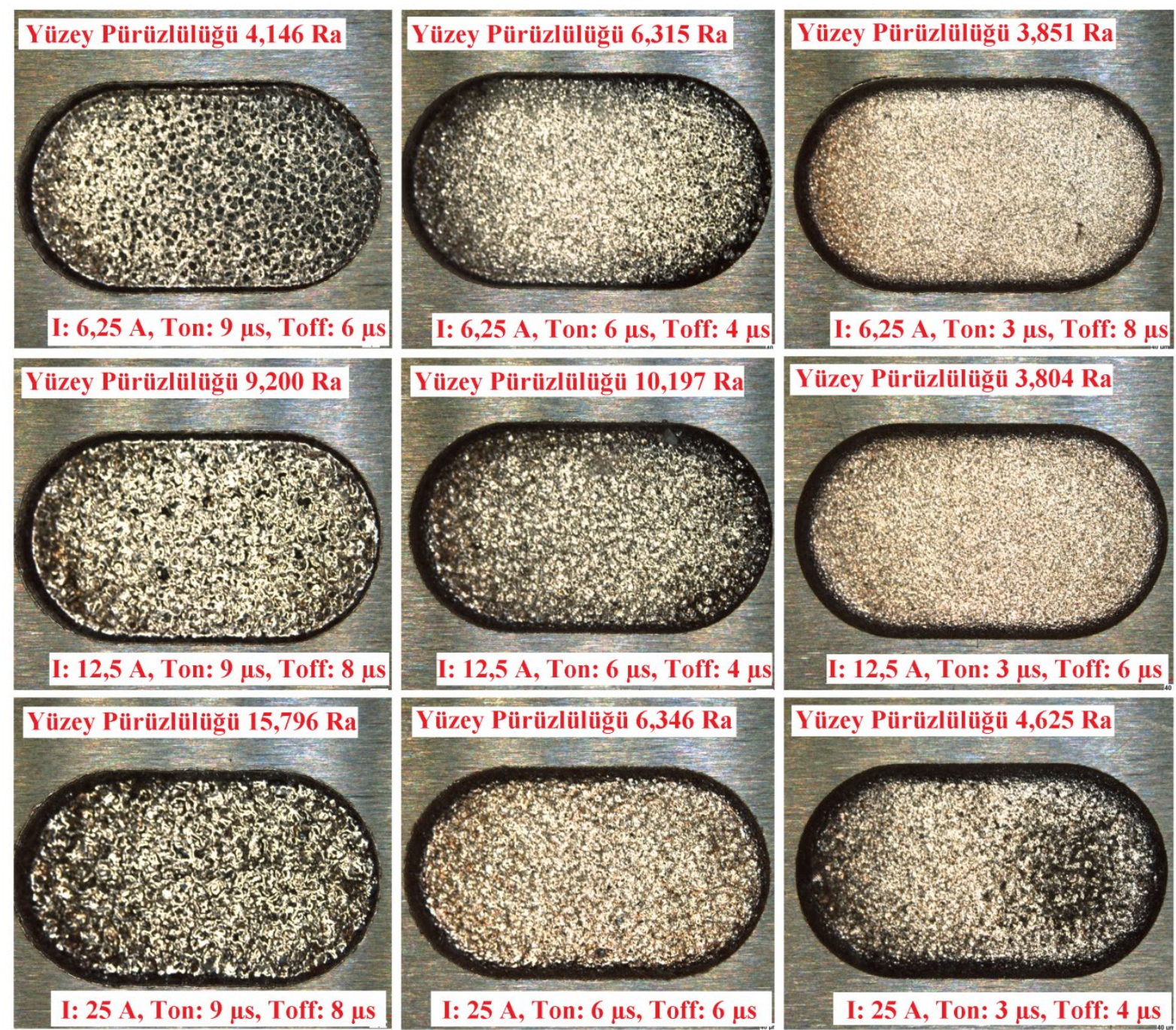

Şekil 5. Deney numunelerinin optik mikroskop görüntüleri

EEİ yönteminde kullanılan dielektrik sıvı ve bu sıvının erozyon ile parça yüzeyinden kalkan curufu ortamdan tahliye etmesi, akımın şiddeti, ark ve bekleme sürelerinin tamamı yüzey pürüzlülüğüne etki etmektedir. Aynı şartlar altında yapılan deneyler ve ortalama değerler neticesinde 
boşalım akımının artması ortalama yüzey pürüzlülüğünü arttırmıştır. Deneyler sonucunda elde edilen en pürüzlü ve en pürüzsüz yüzey incelendiğinde yüksek akım değerleri kullanımında Şekil 6. b'de görüldüğü gibi kerf bölgelerinde malzemenin ergiyerek aktığı ve saçıldığı tespit edilmiştir. Daha düşük akım değerlerinde Şekil 6. a'da görüldüğü gibi keskin hatlar ve temiz bir yüzey elde edilmiştir. EEİ yöntemiyle bakır elektrota verilen formun iş parçası üzerinde oyuk şeklinde oluşturulması neticesinde curuf kalıntıları köşe kısımlarında kalıntı şeklinde tespit edilmiştir bu durum dielektrik sıvının işlenen yüzeylerin köşe kısımlarından curufu yeterli seviyede tahliye edememesi sebebiyledir. İşlenen yüzeylerin topografik yapısı incelendiğinde düşük pürüzlülüğe sahip yüzeylerin ince tane yapısında olduğu, yüzeyde dalgalanma ve oyuklar arttıkça yüzey pürüzlülügünün arttığı tespit edilmiştir.

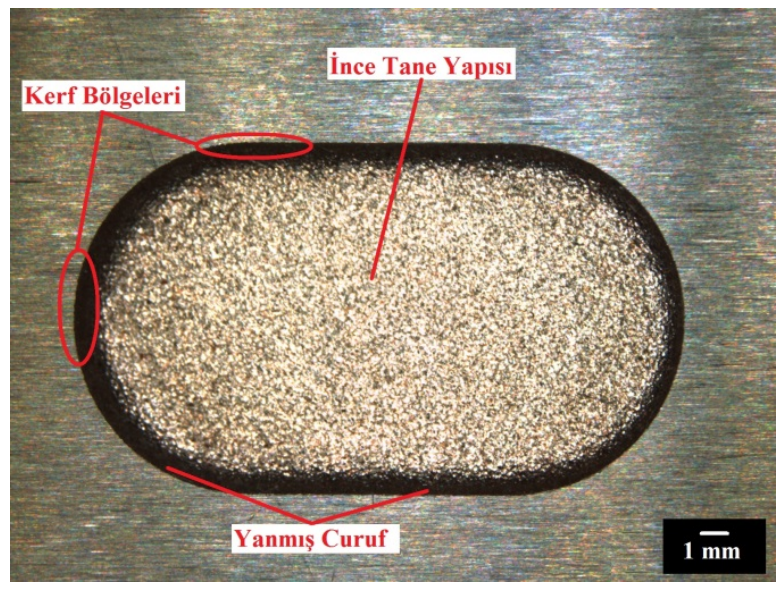

(a)

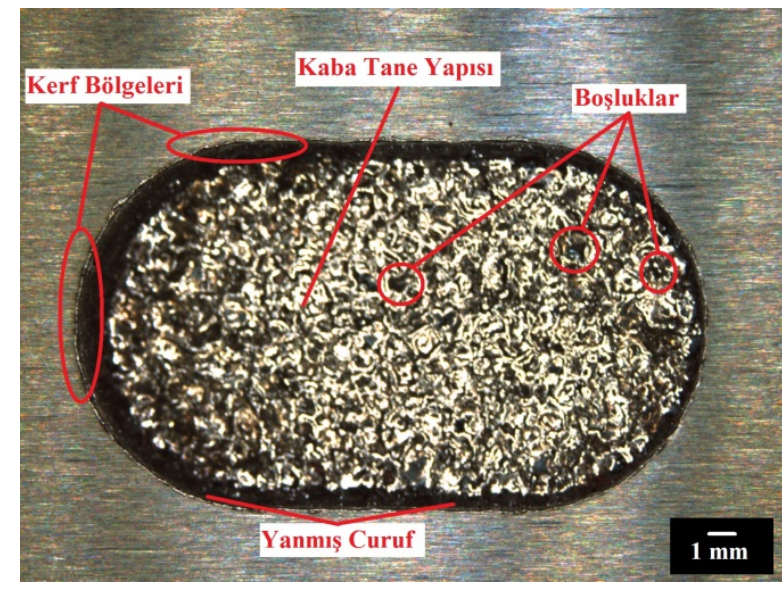

(b)

Şekil 6. Yüzey analizi: (a) En pürüzsüz yüzey (b) En pürüzlü yüzey

EEİ'de elektrot ile iş parçası arasında mekanik bir temas söz konusu değildir; dielektrik bir ortamda sürekli tekrarlayan elektriksel boşalım söz konusudur. Yaklaşık 20,000 ${ }^{\circ} \mathrm{C}$ 'ye ulaşılan 1sı neticesinde iş parçasında erime ve buharlaşma olur. Bu süreçte hiçbir mekanik gerilme meydana gelmez (Torres ve ark., 2016; Sengottuvel ve ark., 2013). EEİ esnasında elektrotların köşe kısımlarında meydana gelen deformasyonlar esas olarak elektrot ucundaki aşırı elektrik yoğunluğundan meydana gelmektedir (Yıldız, 2017). Bu durum elektrotların köşesinde çok fazla aşınmalara sebep olmaktadır (Sundaram ve Rajurkar, 2008). Elektrot malzemesinin erozyon başlangıcındaki form ve ölçüsü EEİ sonrası form ve ölçüleriyle aynı değildir. Bu sebeple iş parçası üzerindeki formun başlangıç ve bitiş ölçüleri farklıdır. Bu durum kerf açısına sebebiyet vermektedir. Seçilen işleme parametrelerinin ortalama kerf açısına ve yüzey pürüzlülüğüne etkileri ve bu etkilerin yanı sıra farklı EEİ proseslerinin işleme süreleri Şekil 7'de gösterilmiştir. Genel olarak boşalım akımının artmasıyla artan boşalım enerjisine bağlı olarak buharlaşan malzeme miktarı artmıştır bu sebeple işleme süresi azalmıştır. Bu durumlar elektrot aşınmasına sebebiyet verdiği için ortalama yüzey pürüzlülüğü ve ortalama kerf açısı artmıştır. Ayrıca bekleme süresi ve vurum süresininde yüzey 
pürüzlülüğü, ortalama kerf açısı ve işleme sürelerine etki ettiği tespit edilmiştir. Düşük akım ve vurum süresi değerlerinde bekleme süresinin artması ile işleme süresi ciddi şekilde artmıştır.

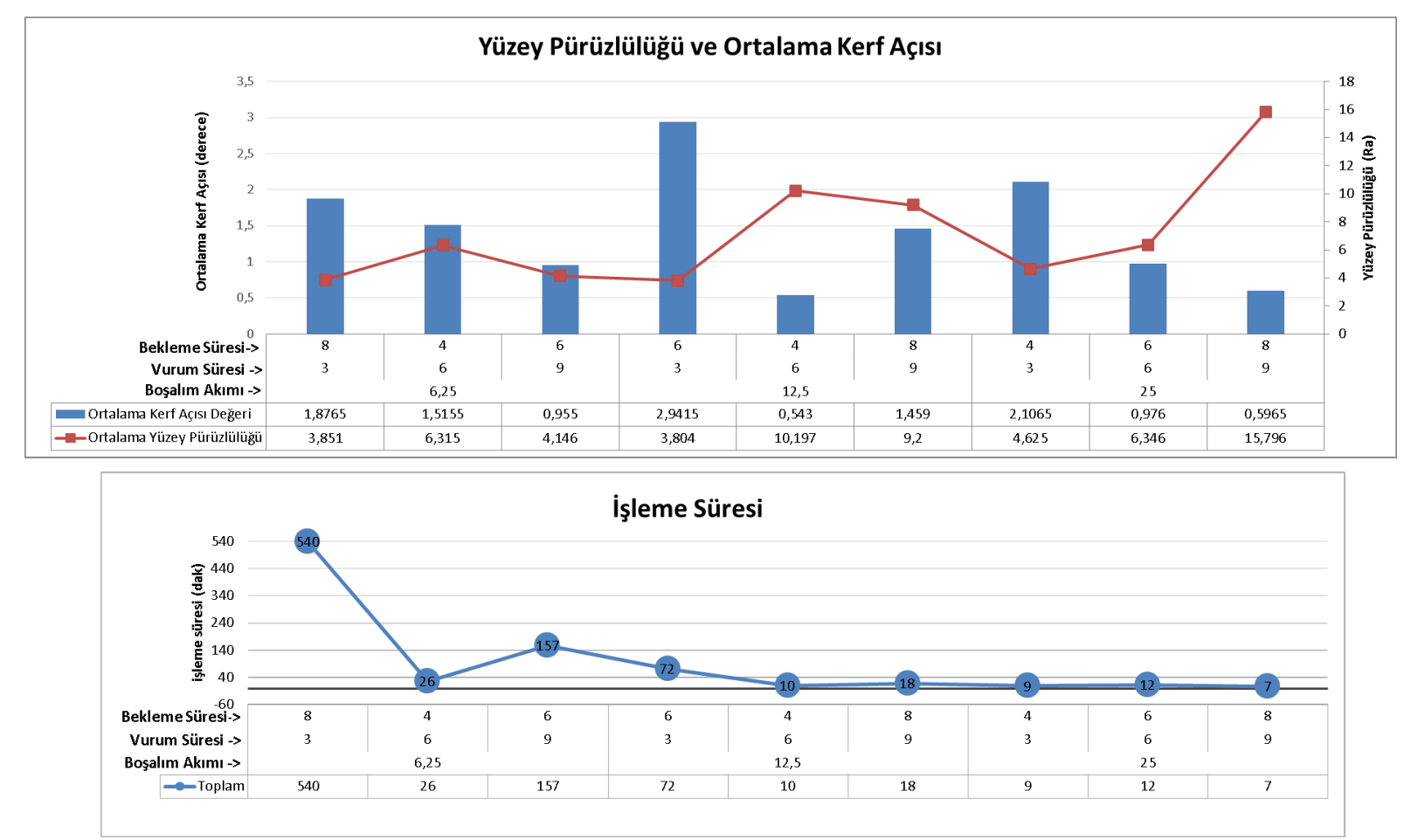

Şekil 7. Test sonuçlarının grafiksel gösterimi

Literatürde bulunan benzer çalışmalar incelendiğinde boşalım akımının yüzey pürüzlülüğüne etki eden en baskın parametre olduğu, savunma sanayisinde kullanılan Ramor 500 zırh çeliğinin EEİ yöntemiyle işlenmesinde Ra yüzey pürüzlülük değerine etkisinin \% 79,07 olduğu belirtilmiştir (Nas, 2020). Başka bir çalışmada, matris malzemesi olarak AA7075 alaşımı içeren metal matris kompozit malzemelerin işlenmesinde boşalım akımının yüzey pürüzlülügüüne etkisi \% 48,77 olarak bildirilmiştir (Uğur ve ark., 2020).

\section{Genel Sonuçlar}

Deneysel çalışmalar neticesinde elde edilen analitik hesaplamalar ve makro analiz sonuçlarına göre;

• EEİ parametrelerinden boşalım akımı, vurum ve bekleme sürelerinin yüzey pürüzlülüğü, kerf açısı ve işlem süresine etki ettiği tespit edilmiştir. Bekleme süresinin artması ile işleme süresi büyük ölçüde artmış boşalım akımının ve vurum süresinin artması ile azalmıştır.

- Boşalım akımının artması iş parçası ve elektrot arasında kıvılcımlanmayı arttırarak noktasal erime ve tahribatı (talaş kopartma) arttırmıştır bunun neticesinde yüzey pürüzlülüğü artmıştır. 
Boşalım akımının \% 100 ve \% 300'lük artışı neticesinde ortalama yüzey pürüzlülüğü sırasıyla \% 62 ve $\% 87$ oranında artmıştır.

- Düşük vurum süresi ve yüksek bekleme sürelerinde elektrot birim zamanda daha fazla çalıştırılarak, elektrodun uç kısımlarında aşırı elektrik yoğunluğu ve kıvılcımlanmadan kaynaklı aşınmalar oluşmuştur bu aşınmalar sonucunda ortalama kerf açısı artmıştır.

- Boşalım akımının ne çok yüksek nede çok düşük olduğu 12.5 A değeriyle $3 \mu$ s vurum süresi ve $6 \mu$ s bekleme süresi parametrelerinin kullanımında en düşük yüzey pürüzlülüğü olan $3.804 \mathrm{Ra}$ değeri elde edilmiştir fakat kerf değerlerinin $\mathrm{T}_{\mathrm{L}}: 3.021^{\circ}$ ve $\mathrm{T}_{\mathrm{w}}: 2.862^{\circ}$ olarak deneylerdeki en yüksek değerler olduğu görülmüştür. Bu durum aşınan iş parçası ve elektrot kalıntılarının ark bölgesinden başarılı bir şekilde tahliyesi sonucu meydana gelmiş; iş parçasının yüzeyinin daha pürüzsüz olması, elektrot yüzeyininin ise daha fazla ark yapması sonucu daha fazla aşınması ile sonuçlanmıştır.

\section{Teșekkür}

Bu çalışmadaki EEİ verilerinin elde edilmesi esnasında EEİ makinasının çalıştırılmasında ve diğer süreçlerde rol alan Haier Europe, Candy-Hoover kalıphane çalışanlarına teşekkür ederiz.

\section{Yazarların Katkısı}

Tüm yazarlar çalışmaya eşit katkıda bulunmuştur.

\section{Çıkar Çatışması Beyanı}

Yazarlar arasında herhangi bir çıkar çatışması bulunmamaktadır.

\section{Araştırma ve Yayın Etiği Beyanı}

Yapılan çalışmada araştırma ve yayın etiğine uyulmuştur.

\section{Kaynaklar}

Abhishek, K., Datta, S., Biswal, B. B., \& Mahapatra, S. S. (2017). Machining performance optimization for electro-discharge machining of Inconel 601, 625, 718 and 825: an integrated optimization route combining satisfaction function, fuzzy inference system and Taguchi approach. Journal of the Brazilian Society of Mechanical Sciences and Engineering, 39(9), 3499-3527. https://doi.org/10.1007/s40430$\underline{016-0659-7}$ 
Bari, P., Chauhan, S., Patil, K., Mhasde, S., \& Dharmadhikari, A. (2017, January). Optimization of electric discharge machining process parameters using carbon nanotubes. In 2017 International Conference on Nascent Technologies in Engineering (ICNTE) (pp. 1-6). IEEE. DOI: 10.1109/ICNTE.2017.7947980

Bin Abdul Rahim, M. A. S., bin Minhat, M., Hussein, N. I. S. B., \& bin Salleh, M. S. (2018). A comprehensive review on cold work of AISI D2 tool steel. Metallurgical Research \& Technology, 115(1), 104. https://doi.org/10.1051/metal/2017048

Guu, Y. H. (2005). AFM surface imaging of AISI D2 tool steel machined by the EDM process. Applied Surface Science, 242(3-4), 245-250. https://doi.org/10.1016/j.apsusc.2004.08.028

Gupta, R., Bibave, P., Shelke, A., Kesarkar, R., Bari, P., \& Chauhan, S. (2016). Optimization of electrical discharge machining process parameters using flushing and drilled tool. Int. Res. J. Eng. Technol., 3(4), 1316-1320.

Kalyon, A. (2019). Elektro Erozyon ile İşlemede Yüzey Pürüzlülüğü ve İş Parçası İşleme Hızının Alüminyum Alaşımı İçin Taguchi Tekniği ile Optimizasyonu. DEUFMD, 21(62), 595-605. DOI:10.21205/deufmd.2019216223

Kalyon, A., \& Fatatit, A. Y. (2019). The Environmental Impact of Electric Discharge Machining. International Journal of Engineering Science and Application, 3(3), 123-129. https://dergipark.org.tr/tr/pub/ijesa/issue/49080/556823

Kalyon, A. (2020). AISI D2 Soğuk İş Takım Çeliğinin Elektro Erozyon Tekniği İle İşlenebilirliğinin Deneysel Olarak İncelenmesi. Mehmet Akif Ersoy Üniversitesi Uygulamalı Bilimler Dergisi, 3(1), 75-86. Doi: d X.doi.org/10.31200/makuubd.494265

Lee, H. T., Hsu, F. C., \& Tai, T. Y. (2004). Study of surface integrity using the small area EDM process with a copper-tungsten electrode. Materials Science and Engineering: A, 364(1-2), 346-356. https://doi.org/10.1016/j.msea.2003.08.046

Lee, S. H., \& Li, X. P. (2001). Study of the effect of machining parameters on the machining characteristics in electrical discharge machining of tungsten carbide. Journal of materials processing Technology, 115(3), 344-358.https://doi.org/10.1016/S0924-0136(01)00992-X

L. Li, Z. Y. Li, X. T. Wei \& X. Cheng (2015). Machining Characteristics of Inconel 718 by Sinking-EDM and Wire-EDM, Materials and Manufacturing Processes, 30:8, 968-973, http://dx.doi.org/10.1080/10426914.2014.973579

Mohanty, C. P., Mahapatra, S. S., \& Singh, M. R. (2014). An experimental investigation of machinability of Inconel 718 in electrical discharge machining. Procedia materials science, 6, 605-611. https://doi.org/10.1016/j.mspro.2014.07.075

Nas, E. (2020). Analysis of the electrical discharge machining (EDM) performance on Ramor 550 armor steel. Materials Testing, 62(5), 481-491. https://doi.org/10.3139/120.111510

Nas, E., Argun, K., \& Zurnacı, E. (2018). AISI 1.2738 Çeliğinin Elektro-Erozyon Tezgahında Bakır ve Grafit Elektrot İle İşlenmesinde İşleme Parametrelerinin Yüzey Pürüzlülüğü Üzerine Etkisinin Deneysel ve İstatiksel Olarak İncelenmesi. Düzce Üniversitesi Bilim ve Teknoloji Dergisi, 6(4), 1082-1093.

Özdemir, M , Yılmaz, V , Dilipak, H . (2015). AISI 1040 Çeliğinin Elektro Erozyon ile İşleme Yöntemiyle Delinmesinde İşleme Parametrelerinin Temel Performans Çıktıları Üzerindeki Etkilerinin İncelenmesi. Gazi Üniversitesi Fen Bilimleri Dergisi Part C: Tasarm ve Teknoloji , 3 (1) , 417-426 . https://dergipark.org.tr/tr/pub/gujsc/issue/7466/98309

Payal, H. S., Choudhary, R., \& Singh, S. (2008). Analysis of electro discharge machined surfaces of EN-31 tool steel. Journal of Scientific and Industrial Research, 67(12) https://www.researchgate.net/publication/242121494

Sengottuvel, P., Satishkumar, S., \& Dinakaran, D. (2013). Optimization of multiple characteristics of EDM parameters based on desirability approach and fuzzy modeling. Procedia Engineering, 64, 1069-1078. https://doi.org/10.1016/j.proeng.2013.09.185

Singh, S., Maheshwari, S., \& Pandey, P. C. (2004). Some investigations into the electric discharge machining of hardened tool steel using different electrode materials. Journal of materials processing technology, 149(1-3), 272-277. https://doi.org/10.1016/j.jmatprotec.2003.11.046

Srithar, A., Palanikumar, K., \& Durgaprasad, B. (2014). Experimental investigation and surface roughness analysis on hard turning of AISI D2 steel using coated carbide insert. Procedia Engineering, 97, $72-77$. https://doi.org/10.1016/j.proeng.2014.12.226

Sundaram, M. M., \& Rajurkar, K. P. (2008). Toward freeform machining by micro electro discharge machining process. In Transactions of the North American Manufacturing Research Institution of SME - Paper Presented at NAMRC 36 (pp. 381-388). (Transactions of the North American Manufacturing Research Institution of SME; Vol. 36). 
Torres, A., Puertas, I., \& Luis, C. J. (2016). EDM machinability and surface roughness analysis of INCONEL 600 using graphite electrodes. The International Journal of Advanced Manufacturing Technology, 84(9), 2671-2688. https://doi.org/10.1007/s00170-015-7880-x

Uğur, A., Nas, E., \& Gökkaya, H. (2020). Investigation of the machinability of SiC reinforced MMC materials produced by molten metal stirring and conventional casting technique in die-sinking electrical discharge machine. International Journal of Mechanical Sciences, 186, 105875. https://doi.org/10.1016/j.ijmecsci.2020.105875

Yıldız, Y. (2017). Biyomedikal Uygulamalar için Magnezyum-Kalsiyum (Mg-0.8Ca) Alaşımının Dalma Elektro Erozyon ile İşlenmesi. Dokuz Eylül Üniversitesi Mühendislik Fakültesi Fen ve Mühendislik Dergisi, 20(59), 336-346. DOI: 10.21205/deufmd. 2018205927

Zappelino, B. F., de Almeida, E. D. S., Krelling, A. P., da Costa, C. E., Fontana, L. C., \& Milan, J. C. G. (2020). Tribological behavior of duplex-coating on Vanadis 10 cold work tool steel. Wear, 442, 203133. https://doi.org/10.1016/j.wear.2019.203133 